\title{
IMIGRAÇÃO NO BRASIL NA LITERATURA PORTUGUESA DO SÉCULO XIX ${ }^{12}$
}

\author{
Mario Luis Grangeia3
}

\section{RESUMO}

Imagens da imigração portuguesa no Brasil têm sido difundidas por escritores dos dois países desde o século XIX. Esta comunicação mostra que os significados atribuídos por autores portugueses desse século incluíram a imigração como fuga, escravatura, sorte, exploração, mal necessário e abandono. Mudanças e permanências nesse imaginário são estudadas a partir do mapeamento de obras de Camilo Castelo Branco, Eça de Queiroz, Gomes de Amorim e Ramalho Ortigão e da perspectiva da sociologia cultural. Eles retrataram a vida de imigrantes no Brasil e retornados na terra natal. A pesquisa realça sobretudo causas, efeitos e reações vinculadas à imigração.

PALAVRAS-CHAVE: Portugueses no Brasil; Literatura portuguesa; Sociologia cultural.

\section{IMMIGRATION IN BRAZIL ON THE PORTUGUESE LITERATURE IN THE NINETEENTH CENTURY}

\begin{abstract}
Images of Portuguese immigration in Brazil have been disseminated by writers from both countries since the 19th century. This communication shows that the meanings attributed by Portuguese authors of that century described immigration as an escape, as slavery, luck, exploration, a necessary evil and as a sort of abandonment. Changes and continuities in this imagery are studied from analyses of works by Camilo Castelo Branco, Eça de Queiroz, Gomes de Amorim and Ramalho Ortigão, and from the perspective of cultural sociology. They portrayed the lives of immigrants in Brazil and of those who returned to their homeland. This research study, which emphasizes above all causes, effects and reactions to immigration, is taken further into the twentieth century.
\end{abstract}

KEYWORDS: Portugueses in Brazil; Portuguese literature; Cultural sociology.

${ }^{1}$ Trabalho submetido em08/08/18 e aprovado em 20/12/18. Para citar este artigo: GRANGEIA, M. L. Imigração no Brasil na Literatura Portuguesa do século XIX.Cadernos de Estudos Sociais, Recife, v.33, n. 2,[in press], jul./dez., 2018. DOI: 10.33148/CES2595-4091v.33n.220181764. Disponível em: < http://periodicos.fundaj.gov.br/index. php/CAD>. Acesso em: dia mês, ano. [v. em edição].

${ }^{2}$ Uma versão anterior foi debatida em agosto de 2018 na IV Jornada de Pesquisadores da Fundação Biblioteca Nacional, na sede da FBN, e no VI Congresso Internacional do Núcleo de Estudos das Américas, na Uerj.

${ }^{3}$ Pesquisador visitante na Fundação Biblioteca Nacional (2017/2018), é doutor e mestre em Sociologia pelo Programa de Pós-Graduação em Sociologia e Antropologia da UFRJ, especialista em Sociologia Política e Cultura (PUC-Rio) e bacharel em Comunicação Social/Jornalismo (UFRJ). E-mail: mario.grangeia@gmail.com 


\section{LA INMIGRACIÓN EN BRASIL EN LA LITERATURA PORTUGUESA DEL SIGLO XIX}

\section{RESUMEN}

Imágenes de la inmigración portuguesa en Brasil han sido difundidas por escritores de los dos países desde el siglo XIX. Esta comunicación muestra que los significados dados por los autores portugueses de este siglo describen la inmigración como una fuga, como esclavitud, suerte, exploración, un mal necesario y como una especie de abandono. Los cambios y permanencias en ese imaginario son estudiados a partir del análisis de obras de Camilo Castelo Branco, Eça de Queiroz, Gomes de Amorim y Ramalho Ortigão, y desde la perspectiva de la sociología cultural. Ellos retrataron la vida de inmigrantes en Brasil y de aquellos regresados a su tierra natal. La investigación, que subraya sobre todo causas, efectos y reacciones a la inmigración, avanza aún por el siglo XX.

PALABRAS CLAVE: Portugueses en Brasil; Literatura portuguesa; Sociología cultural.

\section{INTRODUÇÃO}

Quais imagens os escritores portugueses atribuíram à imigração no Brasil? A questão, que atravessa limites disciplinares das Ciências Sociais, da História e das Letras, é interpelada neste estudo a partir de uma análise de enquadramentos na perspectiva da sociologia cultural. De início, foram mapeados, no acervo da Biblioteca Nacional, livros de ficção e não ficção com representações da vida de portugueses na terra adotiva ou dos retornados na terra natal. Em meio a 15 livros desde o século XIX, discutem-se aqui os seis publicados naquele século.

Os estudos sobre a imigração portuguesa no Brasil têm preterido suas imagens na literatura portuguesa, privilegiando outros objetos e abordagens (há trabalhos sobre esse imaginário na literatura brasileira, mas ainda são raros). Autores no país de origem priorizaram a emigração clandestina, as remessas de dinheiro, engajadores de mão de obra, retornados e tentativas de canalizar emigrantes a colônias africanas (SILVA, 2011). Estudos editados no Brasil frisaram a socialização, empreendedorismo e associativismo dos migrantes.

Há, porém, carência de pesquisas sobre a imigração com base em fontes como textos literários - prevalece de longa data o uso das fontes oficiais, como documentos de diplomacia.

Uma noção de representações populares da imigração e seus participantes foi captada em uma enquete do Datafolha no Rio de Janeiro e em Lisboa às vésperas dos 500 anos da chegada dos portugueses ao Brasil. Foram ouvidas centenas de opiniões de um povo sobre o outro e as qualidades que os brasileiros atribuíram mais eram trabalhador (26\%) e avarento $(19 \%)$ - impressões deixadas por migrantes do início do século XX, quando muitos prosperaram no comércio (FOLHA DE S. PAULO, 1999). 
Além da escassez de estudos com o escopo deste, o que justifica a pesquisa é a própria escala da imigração portuguesa no país. Entre 1884 e 1984, tais imigrantes somaram quase 1,6 milhão (31\%) dos mais de 5,1 milhões de imigrantes oficiais (VILLAS BÔAS; PADILLA, 2007). Se for incluída a emigração clandestina, estima-se que quase 2 milhões de portugueses emigraram só de 1886 até os anos 1970. O auge foi em 1966, com 120 mil saídas registradas (SCOTT, 2012). Apesar disso, persiste um grupo imigrante menos pesquisado do que outros no Brasil, onde a literatura sobre lusos é menos fértil que a voltada aos italianos e japoneses.4

Responder, a partir da literatura portuguesa, à pergunta "como é ser imigrante no Brasil?" e outras nesses tempos de notável "vilanização" de imigrantes - maior no hemisfério norte, observe-se - é uma agenda de estudos não apenas relevante. É uma questão necessária.

Para o mapeamento de livros sobre a imigração na literatura portuguesa, se explorou a bibliografia de autores emigrantes ou não e, em paralelo, se estudaram trabalhos sobre a vida e obra daqueles autores e sobre a literatura dedicada à imigração portuguesa no Brasil.

Do século XIX, são analisados seis livros: "Os brilhantes do brasileiro", de Camilo Castelo Branco (1825-1890), "Ódio de raça", "Aleijões sociais" e "As duas fiandeiras", de Francisco Gomes de Amorim (1827-1891), “As farpas”, de Ramalho Ortigão (1836-1915) e “Uma campanha alegre”, de Eça de Queiroz (1845-1890). Nesse corpus, seis imagens foram atribuídas à migração: fuga, escravatura, sorte, perda, exploração, mal necessário e abandono. Para tanto, deu-se atenção às causas, impactos e reações vinculadas pelos autores à imigração.

- Fuga: emigração em resposta a drama pessoal, resulta em "novos ricos" entre os retornados, alvos ora de piedade, ora de riso de conterrâneos que acabam beneficiados por recursos deles;

- $\quad$ Escravatura: responde à necessidade dos migrantes e interesse dos engajadores, é vista como injustiça e gera lusofobia no Brasil, onde se dá "comércio de carne humana" (AMORIM, 1870);

- Sorte: emigração por uma vida melhor, leva ao excesso de trabalho e, para alguns migrantes, prosperidade, o que faz da migração uma "loteria" onde pessoas são tratadas como bastardas;

\footnotetext{
${ }^{4}$ Vide SciELO e anais de eventos científicos (ANPUH, p. ex.). Estudos da imigração portuguesa costumam citar mais obras sobre o tema editadas em Portugal do que no Brasil.
} 
- Mal necessário: migração tida como responsável por evasão de trabalhadores fortes que, no Brasil, encontram território onde não há liberdade, são desprotegidos e vivem "ódio de raça";

- $\quad$ Exploração: resulta em casos de servidão por dívida e leva a uma massa de ociosos nos dois países (desvalidos no Brasil e inativos em Portugal), despertam arrependimento e lusofobia; e

- Abandono: como nos dois casos anteriores, migração é reação à miséria e, além da evasão rural, gera projetos oficiais anti-emigração e retornados sem vontade de investir na terra natal.

Na próxima seção, são sumarizadas ideias sobre o marco teórico e a metodologia desta pesquisa. Depois, debate-se como foram captadas e analisadas imagens literárias da migração (optou-se por falar em migração, por se reunir visões da imigração tanto quanto da emigração) nas obras daqueles quatro autores. Argumenta-se que os enquadramentos da migração estão vinculados a diagnósticos e prognósticos da questão. Ao fim, realça-se a utilidade do conceito de enquadramentos em trabalhos como este, frisando contribuições a três campos de pesquisa: história das migrações, sem se limitar à historiografia da imigração portuguesa; sociologia cultural, perspectiva menos trabalhada no Brasil do que a sociologia da cultura; ${ }^{5}$ e literatura portuguesa.

\section{DA FUNDAMENTAÇÃO TEÓRICA À METODOLOGIA}

Para estudar obras literárias sobre a imigração, adotou-se a perspectiva da sociologia cultural, que enfatiza a autonomia dos processos culturais, considerando a cultura, significado estruturado coletivamente, como variável independente. Discursos e outros códigos culturais não apenas refletem forças materiais e institucionais, mas são chaves para a compreensão de interações sociais, inclusive relações de poder (ALEXANDER; SMITH, 2000). Desde a “inflexão cultural” da virada dos anos 1980 aos 1990, conceitos de grande alcance empírico para estudar influências da cultura têm sido usados e aperfeiçoados, como o enquadramento.

\footnotetext{
${ }^{5}$ Ao estudarem relações entre o cultural e o social, sociólogos culturais advogam uma noção robusta de cultura, sem tomá-la como um efeito epifenomênico de "fatores não culturais", paradigma teórico usual na sociologia da cultura e criticado por eles. Para avançar além dessa diferenciação a grosso modo, convém ler Lima Neto (2014).
} 
Enquadramentos têm sido definidos como organizadores de pensamento (FERREE et al., 2002) ou ideias e princípios que organizam experiências e orientam ações (GAMSON, MODIGLIANI, 1989; BENFORD; SNOW, 2000). Analistas de enquadramentos comungam da ideia de que eles operam como molduras orientando visões e interpretações do mundo, pois codificam expectativas quanto às relações sociais e efeitos dos atos. "Ao entendermos os frames que indivíduos ou grupos diferentes empregam em interações sociais e processos de decisão, podemos começar a entender a variação de suas interpretações e compreensões" (SMALL et al., 2011, p. 101). Eis uma forma de relacionar cultura e comportamento: quadros não geram comportamentos - indicam relações de restrição-possibilidade, e não causa-efeito.

Estudar como a imigração é enquadrada não só esclarece significados dados a ela, mas aponta possibilidades de ação que se abrem a partir de cada quadro. Afinal, a criação de significados articula diagnósticos e prognósticos e realça ao que atentar ou não. Segundo Ferree e coautores (2002, p. 14), “enquadramentos de questão chamam nossa atenção para certos eventos e suas causas e consequências subjacentes e direcionam nossa atenção para longe das outras". Ao compararem notícias de imprensa sobre o aborto na Alemanha e EUA, viram que o enquadramento "vida fetal" predomina entre alemães; nos EUA, enquadramentos de direitos individuais e pró-aborto e de direitos do feto e antiaborto se chocam.

A análise de enquadramento centrada no conteúdo permite ver como se manifestam os quadros, pois enfocam ângulos discursivos e interpretações. Mendonça e Simões (2002) veem tal traço favorecer a compreensão de controvérsias públicas e alterações de quadros.

O desafio metodológico inicial consistiu em delimitar o universo de obras a analisar. Para responder como a imigração portuguesa no Brasil foi enquadrada, era preciso mapear uma gama expressiva de discursos literários sobre o tema. E, para captar e analisar o percurso de imagens da imigração com exatidão, esse corpus precisava ser heterogêneo. Contando com a riqueza do acervo de literatura portuguesa da FBN, tal seleção foi feita nas seguintes etapas:

- Pesquisa no acervo: a partir de estudo prévio dessa literatura e outro em paralelo às buscas feitas no sistema da FBN, foram captadas 21 obras de ficção e não ficção desde o século XIX;

-Triagem preliminar: foram excluídas oito obras (quatro mais focadas na emigração, um romance sobre uma retornada que não cita a imigração e volumes de poesia, entrevistas e correspondência); e 
- Inclusão de outras obras: se incluíram duas obras de fora do acervo da Biblioteca Nacional.

A fim de responder quais imagens os escritores portugueses atribuíram no século XIX à imigração no Brasil, foi identificado tal imaginário em livros de Camilo Castelo Branco (“Os brilhantes do brasileiro"), Gomes de Amorim (“Ódio de raça”, “Aleijões sociais” e "As duas fiandeiras"), Ramalho Ortigão (“As farpas”) e Eça de Queiroz ("Uma campanha alegre"). ${ }^{6}$ Para analisar e comparar discursos literários, três variáveis foram mais focalizadas:

a) causas: menções feitas às forças responsáveis pelos casos de imigração;

b) efeitos: identificação de repercussões da imigração na origem e destino; e

c) reações: focalizam-se reações declaradas à imigração nos textos sob análise.

\section{MIGRAÇÃO COMO FUGA EM CAMILO CASTELO BRANCO}

A obra camiliana é das mais prolíficas da literatura portuguesa, dando conta de mais de 260 títulos. Ao contrário de outros autores com obras analisadas aqui, Castelo Branco não foi imigrante no Brasil. Se tivesse sido, é provável que tal vivência surgisse com cores menos ou mais vivas nos textos, pois sua vida e obra se articulam de modo notável, como concluíram estudiosos como Houaiss (1986). Ainda assim, muitos personagens camilianos representaram os "retornados" ou "brasileiros", ou seja, portugueses de volta à terra natal. Segundo Matozzi (2016, p. 28-29),

(...) o responsável, a nível literário, da divulgação da personagem do emigrante foi Camilo Castelo Branco, através do notório "brasileiro de torna-viagem". (...) Os "brasileiros" com que o escritor se cruzou no Porto e em todo o Norte de Portugal e que descreveu em muitas das suas obras, eram, na maior parte dos casos, portugueses regressados ricos do Brasil por volta das décadas de 40 e 50 . Muitos deles tinham enriquecido graças ao comércio no Rio de Janeiro ou em outros grandes centros do Brasil, desde as plantações de café na região de São Paulo, passando pelo comércio que unia, desde o período colonial, os portos brasileiros aos do Norte de Portugal. É o caso, por exemplo, do rico negociante e Comendador Bento José Pereira Montalegre de Sentimentalismo e História, que tinha começado a sua carreira a trabalhar no ofício humilde de caixeiro em Pernambuco.

\footnotetext{
${ }^{6}$ Do século XX, nove obras são objeto de análise posterior: as memórias de João Sarmento Pimentel ("Memórias do Capitão"), romances de Ferreira de Castro ("Emigrantes" e "A Selva"), livro de crônicas de Vitorino Nemésio ("O segredo de Ouro Preto e outros caminhos"), romance autobiográfico e coletânea de ensaios de Miguel Torga ("A Criação do Mundo" e "Traço de União"), dois livros de ensaios de Eduardo Lourenço ("O labirinto da saudade" e "A nau de Ícaro”) e a autobiografia de Ruth Escobar ("MariaRuth").
} 
É o caso ainda de dois "novos ricos" que sobressaem em Os brilhantes do brasileiro (1869), onde a filha de um general casada a contragosto com um "brasileiro" vende as joias que ganhou de noivado para pagar o curso de medicina a seu verdadeiro amor, e $A$ brasileira de Prazins (1882), onde uma moça apaixonada por um jovem da aldeia promete ao pai, no leito de morte, que se casará com o tio que voltou rico do Brasil e vai à loucura com tal opção. Como este romance pouco informa dos migrantes - uma das exceções era uma caracterização do tio ("Não se parecia com a maioria dos nossos patrícios que regressam do Brasil com uma opulência de formas almofadadas de carnes socadas" (CASTELO BRANCO, 1995, p.142) -, a análise de enquadramento da imigração no Brasil será aqui concentrada na outra obra citada. Em Os brilhantes do brasileiro, o personagem do título se acredita traído e vítima de adultério após o sumiço dos brilhantes, desfaz o casamento e volta ao Brasil. A nova migração é uma fuga:

E, quinze dias depois, o brasileiro, chorado e lamentado dos amigos, embarcava em um dos seus navios, aproando às praias de Santa Cruz, onde, dizia ele, ia esconder a sua vergonha, associando à sua angústia a franduna rapagoa, Rosa Catraia, que se lhe encostrava ao coração, enjoada com o balanço da galera! (CASTELO BRANCO, 2006, p.78).

Sobre as relações amorosas dos "brasileiros", o narrador diria que eles "eram os usufrutuários mais ou menos exclusivos das peregrinas burguesas do Porto" (CASTELO BRANCO, 1995, p.19), o que sugere que o retorno de emigrantes era visto como uma perspectiva para a ascensão social de burguesas portuenses. Haveria duas fugas: de um território, para homens, e de um certo status, para ambos os sexos.

Tal enquadramento como fuga seria coadunado no capítulo "Amor-próprio" (cap. 19), onde, em carta à irmã, o médico formado graças à venda das joias, a quem "a prosperidade afagava-o no Rio de Janeiro" (CASTELO BRANCO, 1995, p. 78), relatava o encontro com o "brasileiro" na capital: "Sem eu nada lhe perguntar, me disse que deixara Portugal para sempre, por causa de sérios desgostos que lhe dera a mulher. Ouvi-o em silêncio, e tive pena do homem, que me pareceu consternado, posto que nédio e pouco azado para mover à piedade" (CASTELO BRANCO, 1995, p. 78). Tal sentimento, porém, muda com um segundo encontro entre ambos: 
Mas a minha compaixão trocou-se em riso quando ontem o vi em Petrópolis com uma espadaúda mulher que denunciava pertencer à raça forte das nossas mulheres do Minho. Eu ia-me desviando dele, pensando que o embaraçava; mas ele mesmo me chamou para me oferecer de almoçar com tal instância que não pude safar-me. Não me atrevia a perguntar quem era a nossa comensal. (...) Em meio do almoço, o marido exilado da pátria e da esposa que o desonrou, me disse que aquela mulher era o seu aconchego, e a consolação das suas mágoas. Isto me fez um certo engulho, e fiquei depois a pensar na desmoralização daqueles cinquenta anos. Talvez que a mulher cuide lá que o seu esposo anda por cá muito atormentado! Contei-te este caso por achar nele, não direi sal, mas podridão dos costumes contemporâneos, etc (CASTELO BRANCO, 2006, p. 78-79).

A sátira do romancista aos novos ricos de meados do século XIX tinha nesse imigrante um caso singular, ora alvo de piedade, ora de riso. Já o autor da carta à irmã personificava a perenidade de laços dos imigrantes não só afetivos com a terra natal, mas financeiros, como sinaliza a abertura do capítulo "O doente e o doutor" (cap. 20): "Em fins de 1848 perfazia dois anos e meio que Francisco José da Costa demorava no Rio, gozando os proventos de seus muitos trabalhos e créditos. As remessas de dinheiro feitas à irmã denunciavam o propósito de voltar proximamente à pátria." (CASTELO BRANCO, 1995, p. 81).

Os recursos enviados eram, como se lê, sinal de que os portugueses poderiam até ter a migração como fuga, mas nem sempre era definitiva, como indica o trecho seguinte ao recémcitado:

\footnotetext{
Uma instante recomendação fazia ele: era a compra da casinha de Viana, que Francisco ainda via luzente e doirada das ilusões de sua mocidade. Talvez que ali vá acabar os meus dias - escrevia ele. - Tenho posses para mais; no entanto, as minhas esperanças não vão mais longe; e as tuas, pobre Joana, são ver-me resignado na tristeza (CASTELO BRANCO, 1995, p. 81).
}

O domínio da língua e a beleza do estilo estão a serviço do enquadramento de vidas exemplares da época, como os "brasileiros de torna-viagem", comumente descritos com traços burlescos pelo autor.

\section{MIGRAÇÃO COMO ESCRAVATURA E SORTE EM GOMES DE AMORIM}

Em muito de seu teatro, prosa e poesia, Francisco Gomes de Amorim (1827-1891) se mostrou um ativista antiemigração. Essa causa remontava a sua própria biografia: nascido na aldeia litorânea de A-Ver-o-Mar (Póvoa de Varzim), no Minho, emigrou aos 10 anos para 
Belém, onde foi caixeiro até ser maltratado pelos patrões portugueses. $\mathrm{O}$ afinco de aliciadores de emigrantes o marcara, pois, como assinalou no prefácio de Cantos Matutinos (1874, p. 30), “inundavam, como agora, as províncias do norte do reino, agarrando gente por todos os meios possíveis, e não sei mesmo se por alguns impossíveis, porque eram esses homens para grandes dificuldades". Em função das leis contra o tráfico negreiro, muitos comerciantes de escravos africanos tinham passado a negociar escravos brancos, mais baratos que os negros.

Fixando-se no sertão amazônico, onde foi seringueiro, remador e carpinteiro, Amorim encontrou, numa cabana indígena, um poema de Almeida Garrett que o acordou para a poesia. Voltou a Portugal em 1836, sentindo ter sido escravo de patrícios, e teria saudades do Brasil. "Eu amo o teu país, virgem formosa/ Eu amo a tua pátria hospitaleira/ E sinto a minha musa inda chorosa/ Com saudades da terra brasileira" (AMORIM apud CARVALHO, 1998, p. 96).

O teor autobiográfico recorrente na obra de Gomes de Amorim se nota no drama Ódio de raça (1854, publicado em 1869), onde seu alter ego, o caixeiro Manuel, exclamava "Oh! minha pátria, meu querido Portugal, cuidei que te deixava para vir a um país de irmãos, e recebem-me como inimigo! (...) Agora é que eu sei quanto amargam as lágrimas do desterro!" (AMORIM, 1869, p. 25-6). Ambientada num engenho, a peça foi incentivada por Garrett, que se tornara amigo do autor, mostrou-lhe o projeto de lei para cessar a escravidão em territórios portugueses e o aconselhou a realçar os horrores da escravidão para atrair apoio do público a esse projeto. A epígrafe do historiador Ferdinand Denis em Brésil, dava o tom: "Aqui, como em muitos outros lugares, uma questão de raça se tornou uma questão de ódio" (AMORIM, 1854, p. 5).

A denúncia dos patrões dos imigrantes partia do protagonista, o preto cabinda José “primeiro, vendiam só os pretos das suas colônias; agora também acharam meio de vender os brancos, e o Brasil está cheio de portugueses vendidos e comprados por seus irmãos" (AMORIM, 1854, p. 87) - e do próprio autor nas notas da obra: “os piores patrões são os portugueses naturalizados brasileiros. Mas que se há de esperar de homens que, por interesse, renegaram a pátria?" (AMORIM, 1854, p. 177). A questão citada evidencia como ele via dois motivos para a migração: a necessidade e - mal valorado - o interesse. A trama de ódio racial envolvia brancos e mulatos, brasileiros e portugueses e atestava, segundo Pinheiro (2015, p. 426), "que a degradação moral associada e derivada de uma infame estrutura escravocrata fará de todas as personagens suas vítimas". 
A peça Aleijões sociais (1870), encenada antes como Escravatura branca - termo que o povo atribuía à emigração $(\mathrm{CARVALHO}, 1998)^{7}$-, se inspirou num escândalo ligado à imigração no fim dos anos 1850 . O autor contou na introdução que um grupo de portugueses invadira um consulado no Brasil em protesto por mais de 40 mortes num navio chegado com quase 400 pessoas, dobro do limite. Inspetores de saúde foram recebidos por passageiros de joelhos, que reclamavam que as mortes foram por fome, sede e maus tratos do comandante. Ao ouvir as queixas, o cônsul, que já pedira para autoridades locais expulsarem manifestantes, cedeu e fez o capitão ser preso e enviado para Portugal. Na sentença, o réu foi absolvido das mais de 300 acusações. As mortes a bordo foram atribuídas a doenças. O drama não terminou só com essa impunidade. O cônsul ainda pediu a deportação dos portugueses que protestaram.

No primeiro ato, numa aldeia no Minho, o padre Manuel alertava: "Se vos fiais neles [aliciadores], sereis vendidos como escravos para onde cuidais ir buscar fortuna; morrereis em mísero desterro, vítimas de trabalhos brutais e de doenças incuráveis; a maior parte de entre vós não tornará a ver o teto amigo da vossa infância! De cada cem, voltará um, quando muito" (CARVALHO, 1998, p. 43). Antes avesso à ideia de migrar, para não romper a linhagem familiar na lavoura, Domingos Palmeiro se tornou comerciário no Rio de Janeiro e reclamava que no país, em vez de enriquecer sem trabalhar, "a verdade é que se morre trabalhando, como em qualquer outra parte!” (CARVALHO, 1998, p. 106), e que ele vivia pior do que escravos, com donos para sustentá-los. "Que sou eu senão um escravo, e dos mais infelizes e miseráveis" (CARVALHO, 1998, p. 107). O personagem até se queixava da nação pátria, que vendera seus filhos e não fiscalizava as formas da transação, que Domingos equiparava com um "vergonhoso comércio de carne humana" (CARVALHO, 1998, p. 124).

Os novos colonos, na maioria rapazes entre 12 e 20 anos, foram saudados no quinto e último ato pelo padre, no Rio, como outras vítimas; e por um aliciador - um dos vilões, preso na cena final - como mais lotes de caixeiros, trabalhadores e gente "para aplicações diversas". Muitos registros faziam jus a certas imigrações no Brasil - com essa ressalva, não se deixa de ressaltar a heterogeneidade da experiência imigrante -, mas o mercado retratado por Amorim era fiel a Belém, familiar a ele, e não à cena carioca, como criticou Ribeiro (1998), que frisou que a enteada do engajador Dionisio, Eugénia, tinha olhares distintos às escravaturas branca contra a qual discursava como injustiça - e negra - sobre a qual se omitia, "ou melhor, mostra

\footnotetext{
${ }^{7}$ A expressão também acabou usada por P. J. da Costa Braga na peça Paulo e Maria, ou A escravatura branca (Braga, 1859).
} 
que, apesar de todas as suas leituras, é racista, pois, em dado momento, reclama de Domingos (escravo branco por quem sente admiração) ser tratado como um preto" (RIEIRO, 1998, p. 148). A visão da imigração como escravatura branca não foi, porém, a única que se viu na obra de Amorim.

No romance As duas fiandeiras (1881), a imigração era reavaliada na voz de retornado Domingos Rosmaninho, que contraindicava a emigração após ter enriquecido como herdeiro de um patrão amigo sem parentes: "o Brazil é bom, para quem tem lá parentes ricos, ou amigos muito dedicados e bem estabelecidos. É bom... mas lá trabalha-se dez vezes mais do que em Portugal; e quem não estiver resolvido a isso, escusa de ir, porque fará menos do que aqui" (AMORIM, 1881, p. 237). Era como um jogo que o narrador via a emigração portuguesa para o Brasil:

É perfeito jogo de loteria. Por cada cem que se arriscam, volta um, raras vezes rico; mas, em geral, vem sempre doente para o resto da vida. Se há diferença entre esta roleta e a da Misericórdia de Lisboa, é que, na emigração, o número branco é o mais feliz, o que volta; quase todos os que ficam, têm a sorte negra e atroz (AMORIM,1881, p. 186).

O narrador projetava um Portugal vazio se os emigrantes no Brasil tratassem seus pares como o patrão de Domingos: "desde o dia em que a maioria dos brasileiros, por amor dos seus interesses, deixar de tratar os portugueses como irmãos bastardos, não volta cá mais nenhum, e Portugal ficará deserto no espaço de poucos anos" (AMORIM,1881, p. 187). Suas imagens da sorte e escravatura se sobrepunham.

\section{MIGRAÇÃO COMO MAL NECESSÁRIO E EXPLORAÇÃO EM RAMALHO ORTIGÃO}

A emigração para o Brasil foi um dos muitos temas da sociedade e cultura portuguesas que Ramalho Ortigão e Eça de Queiroz abordaram nas crônicas mensais As farpas, pioneiras na crítica social e cultural em Portugal e reunidas depois em As farpas (1887-91, 11 v.), com textos de Ortigão, e Uma campanha alegre (1890-91, 2 v.), de Queiroz. Naqueles textos, os autores compartilhavam a "mesma santa revolta", segundo Queiroz (1890, p. 8), para quem "nos abalançamos a atacar toda uma Sociedade com um punhado ligeiro de ironias douradas". Lamentavelmente, um livro que Ortigão teria escrito sobre o Brasil nunca foi impresso, o que foi até mesmo associado com a mudança de regime político no país em 1889 (ALVES, 2009). 
Pontuais alusões das Farpas ao tema constam já no volume “A vida provincial” (v. 1), onde Ortigão atribuiu à emigração a superação da fome no Minho, graças a recursos enviados por emigrados no Brasil, e citou um diálogo num trem com comentários sobre a relação entre o Minho e o país - como "o minhoto mais forte, o mais robusto e mais inteligente vai para o Brasil”, "graças aos capitães que regressam do Brasil, a província do Minho floresce e prospera" e "em virtude das capacidades subtraídas pela emigração, todas as indústrias minhotas desfalecem por falta de direção inteligente e esclarecida" (ORTIGÃO, 1887, v. 1, p. 153-154). Tais trechos de diálogo revelam visões correntes entre os lusos, como a correlação da emigração a uma crise no Minho e à sua superação - ponto com o qual Ortigão concordara.

No volume "O parlamentarismo" (v.4), ele se referiu à comissão parlamentar destinada a estudar meios de evitar a emigração ao Brasil e definiu o tema como uma "grave questão". Para o autor, os deputados ignoravam os elementos do problema tão complexo da colonização e o relator o abordava com tantos rodeios e recursos retóricos que o tornavam um "caldo de galinha" sem galinha ou caldo. A perda de trabalhadores fortes na emigração foi retomada em "A capital” (v.7) ao expor outros destinos de emigrantes: "se são fortes embarcam em massa e emigram para o Brasil, para a Califórnia ou para as Ilhas Sandwich, para os países ingênuos, jovens e sãos, onde quem trabalha enriquece e quem não trabalha não come" (ORTIGÃO, 1887, v. 7, p. 308). A emigração era vista ora como meio para o enriquecimento, ora para a fome, a depender de cada um.

A emigração para o Brasil ocupa no volume 10 (“Aspectos vários”) um papel central em mais de uma Farpa de Ortigão, para quem “o Brasil é-nos duas vezes nocivo: nocivo pelos braços que nos leva, e nocivo pelo dinheiro que nos manda" (ORTIGÃO, 1887, v. 10, p. 101), o que é ilustrativo da imagem da perda. Os "brasileiros", por sua vez, seriam um grupo de apátridas, como notou na Farpa com um tipo de glossário ao imperador do Brasil em viagem a Portugal:

O brasileiro. (...) Há dias líamos no registo dos leitores de uma biblioteca o seguinte: Fulano de tal - profissão, brasileiro - naturalidade, Mesão Frio. Este, imperial senhor, é o nosso brasileiro. (...) Perfeitamente respeitáveis pela sua iniciativa e pelo seu trabalho, constituem uma espécie de tribo, sem pátria que os adote, porque em Portugal chamam-lhes brasileiros, e no Brasil chamam lhes galegos. São esses que aí vão de bengalas de unicórnio na mão e alfinetes de brilhantes no peito das camisas (ORTIGÃO, 1887, v. 10, p. 23, grifos no original). 
Não bastasse a desidentificação com pátrias, o colono português foi visto, nessa Farpa de dezembro de 1872, como o mais desprotegido e mais detestado dos migrantes europeus: "pesa ainda hoje sobre ele o velho ódio de raça" (ORTIGÃO, 1887, p. 65) - note-se aqui a expressão já adotada por Gomes de Amorim no título de uma de suas peças. Ortigão ainda contrastou as imigrações no Brasil e nos Estados Unidos realçando que quem desembarcava na América inglesa recebia a posse do solo, uma primeira garantia de liberdade ausente no Brasil, onde "a constituição feudal da propriedade entregou metade do país aos senhores de escravos" (ORTIGÃO, 1887, p. 64) - tal designação aos fazendeiros não é fortuita, pois colonos portugueses se aproximam, nessa retórica, dos escravos (e não só, como se lerá, pela falta da liberdade garantida na terra). Outro diferencial americano era facultar a todos a naturalização, ao custo de cinco dólares, o que Ortigão preferia não ver noutro solo. "O Brasil teria por esta simples medida dessangrado Portugal dos seus espíritos mais cultos e das suas inteligências mais vivas, assim como o tem já empobrecido, pela absorção das mais enérgicas das suas forças físicas” (ORTIGÃO, 1887, p. 77).

O enquadramento da imigração como exploração, conforme abordo neste estudo, fica mais em evidência na descrição do contato inicial entre colonos lusos e fazendeiros no Brasil:

O colono português, engajado, como se costuma dizer, pelos delegados dos fazendeiros brasileiros, e escolhido entre a mocidade mais vigorosa, mais ativa e mais forte das províncias do Minho e de Trás-os-Montes, é acolhido no Brasil, no Rio de Janeiro quase sempre, por um senhor esquivo, desconfiado, que vê nele um capital seu exposto aos riscos da deserção ou da fuga, ao iminente perigo da enfermidade e da morte: é preciso explorá-lo à pressa e fazê-lo render de pronto. Daí as tarefas mais violentas e pesadas impostas desde logo ao colono que chega.

O engajado por sua parte entra na colônia esmagado por uma dívida assustadora - o preço da sua viagem, o passaporte, a folha corrida, o enxoval, a passagem, os alimentos, os remédios, as visitas do médico, as custas de instalação etc, - outras tantas quantias abonadas pelo senhor, a quem tem de pagar o capital, amortização e juro de 6 por cento. Ele, com a sua inteligência e a sua atividade, é portanto, desde então, uma cousa que está pertencendo a outrem. Mete pela primeira vez a sua enxada na terra do exílio com a amargurada consciência de quem já não trabalha nem tão cedo tornará mais a trabalhar para si. Neste momento ou se revolta e é um criminoso, ou se submete e é um escravo. (ORTIGÃO, 1887, v. 10, p. 67-68)

Frente a tal quadro, o autor relatou que os rapazes transmontanos e minhotos cediam à força, resignando-se no desalento e na desgraça, e tomavam-se da nostalgia, de um sentimento instintivo da pátria penetrante e profundo. A natureza de traços novos e fantásticos lhes dava 
“perspectivas longínquas e nublosas” (ORTIGÃO, 1887, p. 69) para verem o passado, a família e a pátria.

Além de ser tomado como um explorado, esse imigrante português que emerge na fala de Ortigão é objeto de uma hostilidade que o vitima fisicamente (sol chamejante, umidade das noites, miasmas febris do solo e exalação mefítica dos pântanos) e moralmente (estranheza dos hábitos e costumes, isolação, tristeza, saudade e impotência absoluta da reação individual contra o poder dos fazendeiros). A força das fazendas no Brasil é equiparada à dos bancos em Portugal, pois responderiam por fazer a lei, a justiça e o direito. A influência do capital e da propriedade só diferia num fato, segundo ele (ORTIGÃO, 1887, p. 70):

em Portugal ela [essa influência] é contrastada pelas benéficas resistências de alguns milhares de cidadãos que mantêm a liberdade por meio da independência facultada pelo trabalho; no Brasil não, porque no Brasil quem trabalha é escravo, e a quantidade chamada povo não existe (Grifo nosso).

A crítica incisiva precedia a menção à ideia do cônsul de Portugal no Rio de Janeiro de propor a nulidade de contratos entre proprietário brasileiro e colono português sem a chancela consular. Desse modo, o colono estaria mais esclarecido e com menor risco de comprometerse por ignorância numa transação leonina a sua liberdade e a sua vida. A imagem do imigrante como mercadoria sobressaía adiante no texto:

o colono português engajado para o trabalho dos campos é sublocado pelo fazendeiro que o engajou a outros fazendeiros, que pagam um tanto pelo trabalho dele ao seu primitivo possuidor. Os colonos passam deste modo de mão em mão como uma cousa alugada ou vendida (ORTIGÃO, 1887, p. 73).

Muitas dívidas com os senhores não eram quitadas e, segundo o autor, os colonos morriam e os filhos herdavam sua servidão.

Um destaque feito sobre a maior presença feminina entre emigrantes dos Açores dizia respeito à correlação entre traços físicos das colonas e sua empregabilidade: "uns preferem as louras, outros as morenas. As mais bonitas são as que se acomodam mais depressa" (ORTIGÃO, 1887, p. 74). Em qualquer gênero ou idade, os imigrantes sem trabalho se sujeitavam à miséria e às soluções mais baixas e aviltantes para poderem comer. Tal estado se agravava ainda porque, em vez de recorrer a esses preteridos, quem precisava de portugueses esperava a embarcação seguinte. No Rio de Janeiro, a massa crescente de relegados se aglomerava em casas aqui conhecidas como cortiços e que Ortigão definia ao leitor português 
como "mais afrontosa das vergonhas nacionais", "corolário vivo da nossa decadência", “comentário profundo da nossa inépcia" e "espelho do nosso vício, do nosso desleixo, da nossa corrupção" (ORTIGÃO, 1887, p. 74-75).

A imigração era tida como tão traumática que ele alegou que o arrependimento comum entre portugueses faria os navios voltarem cheios de gente a Portugal se fossem oferecidas passagens aos emigrados arrependidos. A verve irônica do cronista tinha por objeto não tanto a realidade portuguesa responsável pela emigração, mas a situação do outro lado do Atlântico:

Caso extraordinário e verdadeiramente inexplicável: Até hoje a única oposição à emigração de portugueses para o Brasil tem sido feita unicamente pelo Brasil! Nunca lho agradeceremos com suficiente gratidão. Parece que é ele o que tem estado constantemente querendo, pelo que diz respeito às colônias, colonizarnos a nós antes de se colonizar a si mesmo. O Brasil tem denotado sempre pela sua política, pela sua legislação, pela mesma arte, pela sua literatura, pela sua opinião pública e pela sua imprensa, que ele tem dos emigrados esta compreensão fabulosamente estranha: que quem os perde não é quem os dá, mas quem os recebe. Na análise singelamente gramatical dos elementos da sua prosperidade, a América brasileira não tem sabido achar - o agente.

Ora nós é que não estamos certamente seguros, se continuarmos a repousar como até agora num tal ou qual equilíbrio econômico que não tem mais fundamento do que um grosso erro brasileiro de sintaxe administrativa. (ORTIGÃO, 1887, v. 10, p. 77-78)

Ortigão dizia em seguida vislumbrar um país riquíssimo de um grande povo quando a escravatura desaparecesse e a sociedade se baseasse na liberdade e justiça, e não na servidão. A paz e a civilização resultariam, segundo ele, da transformação econômica do Brasil fundada na liberdade, na justiça e "no grande sentimento americano da confraternização universal de todos os espíritos e de todos os povos" (ORTIGÃO, 1887, p. 80). Eis a receita do autor ao avanço do país.

Abordada naquela Farpa de dezembro de 1872, a vida do português no Brasil voltou a ser referida, de modo indireto, na Farpa de janeiro de 1874, onde Ortigão rebatia o historiador Alexandre Herculano, citado como favorável à emigração por ela reverter 3.000 contos anuais a Portugal - dado que, segundo o autor, não tinha fonte apontada por Herculano, assim citado:

Qual é, porém, o teor da vida, em geral, do português do Brasil, do futuro brasileiro de Portugal? É o forcejar incessante, pertinaz, por acumular capitais, reduzindo ao estritamente indispensável a satisfação das suas necessidades. Dedica à prosperidade da indústria, da agricultura ou do comércio daquelas 
regiões a menor parte que pode do fruto do seu trabalho. A sua ideia constante, inflexível, tenaz, é voltar rico, ou pelo menos abastado. E volta. Se, cansado de sacrifícios e trabalho, quer gozar, é à indústria, à cultura e ao comércio do seu país, que atira às mãos cheias o ouro que ajuntou. Se a sede do ganho não se extinguiu nele, esse ouro converter-se-á em capital produtivo. (HERCULANO apud ORTIGÃO, v. 10, p. 87-88)

Em resposta a esse foco do historiador na austeridade do imigrante e na compensação à terra natal, Ortigão frisou que o dinheiro nunca seria um germe da prosperidade, consistindo num elemento de corrupção. Para embasar seu argumento, recorreu a um paralelo com a falta de ganhos da Prússia com a entrada de milhões franceses acumulados por seus emigrantes lá.

Os capitais do Brasil não aumentam a prosperidade nem a riqueza nacional. $\mathrm{O}$ dinheiro brasileiro não circula aqui senão em permutações. Para que o dinheiro do Brasil se transformasse para nós em riqueza pública, seria preciso que ele viesse aumentar a população em vez de a diminuir, cultivar a terra, espalhar o trabalho. Não é isso o que sucede. O emigrado português que regressa do Brasil não vem produzir, vem descansar. Quando o sábio nos diz que é à indústria, à cultura e ao comércio do seu país que o brasileiro atira às mãos cheias o ouro que ajuntou, o sábio divaga no lirismo, delira na retórica. (ORTIGÃO, v. 10, p. 89)

Ao criticar Herculano, Ortigão atacava ainda o próprio "brasileiro", denominação que, a seu ver, era adotada por quem retornava a Portugal apenas com a ociosidade e os juros de seus capitais, e quase nunca com eles, mantidos do outro lado do oceano, onde o negócio era cuidado por um administrador associado. Suscitando a questão sobre o que fazia o português no Brasil, o cronista respondia que

exerce a temperança e o trabalho, lança os mais sólidos e profundos alicerces à civilização e à felicidade em um país estranho. Que traz ele à pátria? Traz-lhe o dinheiro, a ociosidade, a propensão para gozar - causas que o sublime historiador considera os mananciais da riqueza pública (ORTIGÃO, v. 10, p. 90 , grifo no original).

Como se lê, o migrante entra neste debate menos como tema da reflexão de Ortigão, e mais como peça para a crítica a Herculano. Como o autor do presente estudo não se debruçou sobre o texto do historiador, evita avançar nesse choque de ideias e toma igual cautela com a Farpa de março de 1873, réplica ao folheto "Duas palavras aos leitores de Farpas", de autor anônimo que se diz brasileiro patriota (nela, Ortigão reafirma tese anterior sobre a emigração ao Brasil e rebate ideias do referido folheto). 


\section{MIGRAÇÃO COMO MAL NECESSÁRIO E ABANDONO EM EÇA DE QUEIROZ}

Quando As Farpas foram reeditadas em volumes, em 1887, Ramalho Ortigão pediu ao ex-colaborador Eça de Queiroz para revisar os textos escritos por ele, que decidiu reunir suas crônicas, feitas em 1871 e 1872 antes de se tornar cônsul, nos volumes de Uma Campanha Alegre, publicados em 1890 e 1891 (MATOZZI, 2016). Ele tratou da emigração para o Brasil em "O governo e a emigração" (vol. 1), "O brasileiro" (vol. 2), bem como em obras de ficção.

O olhar de Queiroz sobre a emigração em Portugal é resumido no segundo parágrafo de "O governo e a emigração": "a emigração entre nós é decerto um mal” (QUEIROZ, 1890, p. 357). Isso ocorreria devido ao perfil dos emigrantes (os mais enérgicos e decididos), o que levou à perda de "raras vontades firmes" e "poucos braços viris". Enquanto os ingleses partiam até a Austrália e a Índia movidos pelo espírito de atividade e de expansão e voltavam para servir seu país após o acúmulo de vontade, experiência e dinheiro, os portugueses teriam emigrado para sair da miséria e retornavam sem gana de investir. "Em Portugal a emigração não significa ausência - significa abandono. (...) o emigrante que volta, provido de boa fortuna, vem ser um burguês improdutivo, uma inutilidade a engordar” (QUEIROZ, 1890, p. 358). A forte crítica à emigração, feita a partir de notícia sobre um engajador para Nova Orleans, precedia o ataque à tentativa governamental de incentivar migrações internas para a região do Alentejo, além de seu elogio à recomendação oficial para as autoridades buscarem impedir a emigração.

Diante deste grave problema, a emigração, tendo de examinar as condições do país agrícola, de estudar o meio de organizar o trabalho, de regularizar uma emigração interior, de empregar os braços ociosos, de converter em vantagem nacional a energia nativa da população, de obstar ao enfraquecimento do país pela perda da sua riqueza viva, diante destes problemas - o governo volta-se para o regedor e, por toda a ideia, por toda a ciência, lança esta ordem: "A respeito dos colonos, o melhor é fechá-los à chave!"

Como solução a um problema econômico - o governo acha uma fechadura. A governação do Estado torna se questão de serralharia! Um trinco é um princípio: um parafuso uma instituição! Como vós sois grandes! Deixai-vos ver bem de frente... Ah! sois imensos! Mas Sancho Pança - era maior. (QUEIROZ, 1890, p. 365-366)

A crônica de fevereiro de 1872 foi dedicada por Queiroz à figura do "brasileiro", que ele definiu como o português emigrante que voltou rico do Brasil e se tornou "entre nós o tipo de caricatura mais francamente popular", tal como ele notava com outros tipos em cada povo. "Nós temos o Brasileiro: grosso, trigueiro com tons de chocolate, pança ricassa, joanetes nos 
pés, colete e grilhão d'ouro, chapéu sobre a nuca, guarda-sol verde, a vozinha adocicada, olho desconfiado, e um vício secreto" (QUEIROZ, 1891, p. 96). O estereótipo cômico de brasileiro se prestava, segundo o escritor, aos romances românticos (como pai achinelado e ciumento), a comédias salgadas ("gordalhufo amoroso") e mesmo a anedotas (marido traído de tamancos).

O cronista prosseguia notando que não se atribuem ao "brasileiro" qualidades fortes ou finas, inteligência e coragem, e que ele era tido, na tradição popular, "como aquelas abóboras de agosto que sofreram todas as soalheiras da eira" ou "os eternos toscos da rua do Ouvidor". Após citar condições em que se imaginariam tais brasileiros (donos de prédios grotescamente sarapintados, frequentadores de hotéis sujamente lúgubres e outras), realçou que "o brasileiro, o rico torna-viagem é hoje para nós o grande fornecedor do nosso riso" (QUEIROZ, 1891, p. 97). Por fim, Queiroz se opôs a fazerem do "brasileiro" motivo de riso, o que ele considerou uma injustiça, e expôs a tese do "brasileiro" como uma expansão do português, sendo ele dilatado pelo calor.

O que eles são, expansivamente - nós o somos, retraidamente. As qualidades internadas em nós, estão neles florescentes. Onde nós somos à sorrelfa ridiculitos eles são à larga ridiculões. Os nossos defeitos, aqui sob um clima frio, estão retraídos, não aparecem, ficam por dentro: lá, sob um sol fecundante, abrem-se em grandes evidências grotescas. Sob céu do Brasil a bananeira abrese em fruto e o português rebenta em brasileiro. Eis o formidável princípio! O Brasileiro é o Português desabrochado (QUEIROZ, 1891, p. 98).

Nessa comparação tão irônica, o português seria um brasileiro que o clima não deixou desabrochar; sob o sol dos trópicos, seu germe de brasileiro brotaria em diamantes de peitilho, calos e prédios respingados de verde. A prova dada por Queiroz para a tese seria usar o verão, em que o "brasileiro interior tende a florir, a desabrochar, a alastrar em cachos" (QUEIROZ, 1891, p.100).

$\mathrm{O}$ autor sugeria aos portugueses se reconhecerem nos "brasileiros" como a si próprios ao sol e concluía que o português ria do "brasileiro", mas buscava viver à custa dele. "Quando vês o brasileiro chegar dos Brasis estalas em pilherias: - e se ele nunca de lá voltasse com o seu bom dinheiro morrias de fome!” (QUEIROZ, 1891, p. 101). O tom seguia jocoso na avaliação de que duas abordagens correntes dos brasileiros colidiam: a troça em conversas entre amigos no café e a glorificação desse emigrante retornado no jornal, discurso ou sermão - "em cavaqueira é o macaco; na imprensa é o nosso irmão d'além-mar" (QUEIROZ, 1981, p. 102). Eis a conclusão bem-humorada de Queiroz, que finaliza propondo ao brasileiro boicotar o lisboeta, fechando-lhe o bolso, portas de seus prédios e não pisando em hotéis 
locais - não deixa de ser um desfecho que caracteriza o emigrante luso como uma espécie de "mal necessário" para sua pátria natal.

\section{DISCUSSÃO}

Para captar imagens da imigração no Brasil em obras de portugueses, foram analisados livros de Camilo Castelo Branco, Gomes de Amorim, Ramalho Ortigão e Eça de Queiroz a fim de mapear suas referências sobre migrações a vidas dos migrantes, em seu país de destino ou retorno. A natureza dos livros estudados - ficção nos dois primeiros autores e não-ficção nos outros dois - pode implicar vieses à análise, pois a frequência das menções às migrações (e a suas causas, impactos e reações) varia em função do caráter ficcional ou não dos textos.

O Quadro abaixo resume a comparação entre os captados enquadramentos da migração:

Quadro 1 - Imagens da migração na literatura portuguesa (séc. XIX)

\begin{tabular}{|c|c|c|c|}
\hline & Causas & Impactos & Reações \\
\hline Fuga & $\begin{array}{l}\text { Drama pessoal move a } \\
\text { mudança de território }\end{array}$ & $\begin{array}{l}\text { Criação de "novos ricos" e } \\
\text { casais para ascensão social }\end{array}$ & $\begin{array}{l}\text { Migrantes geram piedade e } \\
\text { riso; gratidão por remessas }\end{array}$ \\
\hline Escravatura & $\begin{array}{l}\text { Necessidade dos migrantes } \\
\text { e interesse dos engajadores }\end{array}$ & $\begin{array}{l}\text { "Vergonhoso comércio de } \\
\text { carne humana" (Amorim) }\end{array}$ & $\begin{array}{l}\text { Percebida como injustiça e } \\
\text { "ódio de raça" no Brasil }\end{array}$ \\
\hline Sorte & $\begin{array}{l}\text { Busca de condição de vida } \\
\text { melhor }\end{array}$ & $\begin{array}{l}\text { Maior carga de trabalho no } \\
\text { Brasil; prosperidade de uns }\end{array}$ & $\begin{array}{l}\text { Migrante tratado como um } \\
\text { bastardo }\end{array}$ \\
\hline $\begin{array}{l}\text { Mal } \\
\text { necessário }\end{array}$ & \multirow{3}{*}{$\begin{array}{l}\text { Miséria em certas regiões e } \\
\text { busca por oportunidades }\end{array}$} & $\begin{array}{l}\text { Evasão de trabalhadores } \\
\text { fortes (novos "sem pátria") }\end{array}$ & $\begin{array}{l}\text { Falta liberdade e proteção; } \\
\text { e "ódio de raça" no Brasil }\end{array}$ \\
\hline Exploração & & $\begin{array}{l}\text { Servidão por dívida, massa } \\
\text { ociosa no Brasil e Portugal }\end{array}$ & $\begin{array}{l}\text { Arrependimento para lusos } \\
\text { e aversão entre brasileiros }\end{array}$ \\
\hline Abandono & & $\begin{array}{l}\text { Retorno de emigrantes não } \\
\text { investidores }\end{array}$ & $\begin{array}{l}\text { Anseio entre políticos por } \\
\text { evitar emigração }\end{array}$ \\
\hline
\end{tabular}

Fonte: elaboração deste autor.

Cada imagem da migração é definida com base em causas, efeitos e reações atribuídas ao processo. Nas três primeiras imagens, presentes em obras de Castelo Branco e Amorim, as 
causas têm muito em comum, mas se notam nuances nos discursos literários. No segundo trio, notável em Ortigão e Queiroz, a miséria e a busca de oportunidades constituem causa comum.

Os impactos atribuídos à migração variaram entre os detectados no Brasil, como maior carga de trabalho e "vergonhoso comércio de carne humana", ou em Portugal, como a criação de um grupo de "novos ricos" com perfil sobretudo ocioso (imagens da fuga e exploração). As reações à migração abrangeram desde a lusofobia ("ódio de raça" no Brasil e aversão aos retornados ou "brasileiros" em Portugal) até o anseio político por evitar a emigração no país europeu, passando pelo tratamento entre o riso e a piedade aos portugueses de torna-viagem.

Embora se mostre tão profícua neste estudo, esta tipologia é mera construção analítica, como em outros casos, e pode até ser revista à luz das obras do século XX a serem analisadas.

\section{CONSIDERAÇÕES FINAIS}

Uma contribuição deste estudo foi mapear obras de ficção e não ficção da literatura portuguesa que representam a vida dos imigrantes no Brasil ou a experiência dos retornados. A partir do levantamento em livros editados no século XIX, foi possível analisar mudanças e continuidades em imagens literárias da emigração portuguesa para o Brasil. Tanto o mapeamento das obras literárias como a análise de enquadramentos da migração ofereceram novos olhares a esse processo rico e de longa duração que incluiu a chegada de portugueses em solo brasileiro, mas, em muitos casos, sobretudo no século XIX, a volta dos "brasileiros".

Quatro autores proeminentes na literatura portuguesa ajudaram a criar o imaginário da migração para e no Brasil daquele século: Camilo Castelo Branco, Eça de Queiroz, Gomes de Amorim e Ramalho Ortigão. Enquanto Castelo Branco e Amorim usaram sua ficção em prosa e no teatro para representar a migração com contornos de fuga, escravatura ou sorte, Ortigão e Queiroz enquadraram o tema como mal necessário, exploração e abandono em suas crônicas.

O estudo de imagens literárias da imigração portuguesa no Brasil ilumina formas como ela foi significada por literatos e, em dado momento, por seus leitores. Se considerarmos que essa migração tem sido amplamente estudada sobretudo pelos aspectos materiais do deslocamento, como na discussão das remessas e empreendedorismo dos migrantes, se conclui que tal foco à dimensão simbólica da imigração é um olhar não apenas original, mas igualmente bem-vindo. 


\section{REFERÊNCIAS}

ALEXANDER, J. C.; SMITH, P.. Sociología cultural o sociología de la cultura? Hacia un programa fuerte. In: ALEXANDER, J. C. Sociología cultural: formas de clasificación en las sociedades complejas. Barcelona: Anthropos, 2000. p. 31-54.

ALVES, A. Ramalho Ortigão e o culto dos monumentos nacionais no século XIX. 2009. 586f. Tese (Doutorado em História na Especialidade de Arte, Patrimônio e Restauro) -. Instituto de História da Arte, Departamento de História, Falculdade de Letras, Universidade de Lisboa, Lisboa, 2009.

AMORIM, F. G. de. Ódio de raça. Lisboa: Typographia Universal, 1869.

Aleijões sociais (e $\mathrm{O}$ casamento e a mortalha no ceo se talha). Lisboa: Typographia Universal, 1870.

. Cantos matutinos.3. ed. Porto;Braga: Livraria Internacional, 1874[1858].

. As duas fiandeiras: romance de costumes populares. Lisboa: Empreza Horas

Romanticas, 1881.

BENFORD, R. D.; SNOW, D. A. "Framing Processes and Social Movements: An Overview and Assessment". Annual Review of Sociology, v. 16, p. 611 - 639, 2000.

BRAGA, P. J. da C. Paulo e Maria, ou A escravatura branca. Lisboa: Typographia de Leal, 1859.

CARVALHO, J. R. C. da C. O Brasil na vida e na obra de Francisco Gomes de Amorim. 1998. 152f. Dissertação (Mestrado em Estudos Portugueses e Brasileiros) - Universidade do Porto, Porto, 1998.

CASTELO BRANCO, C. A brasileira de Prazins: cenas do Minho. Rio de Janeiro: Nova Fronteira, 1995.

Os brilhantes do brasileiro. Rio de Janeiro: Escala, 2006.

FERREE, M. M. et al. Shaping Abortion Discourse: Democracy and the Public Sphere in Germany and the United States. Cambridge: Cambridge University Press, 2002.

FOLHA DE S. PAULO. Imagem de trabalhador vem do dono da padaria. Folha de S. Paulo. 22/04/1999. Disponível em: <www1.folha.uol.com.br/fol/brasil500/500_7.htm>. Acesso em: 11 abr. 2018.

GAMSON, W.; MODIGLIANI, A. Media discourse and public opinion on nuclear power: a constructionist approach. American Journal of Sociology. v. 95, n. 1, p. 1 - 37, 1989.

LIMA NETO, F. Cultural sociology in perspective: Linking culture and power. Current Sociology Review. v. 62, n. 6, p. 1-19, 2014. 
LOBO, E. M. L. Imigração portuguesa no Brasil. São Paulo: Hucitec, 2001.

MATOZZI, M. Portugueses de torna-viagem: a representação da emigração na literatura portuguesa. 2016. 290 f. Tese (Doutorado em Patrimónios de Influência Portuguesa) Instituto de Investigação Interdisciplinar, Universidade de Coimbra, Coimbra, 2016.

MENDES, J. S. R. Laços de sangue: privilégios e intolerância à imigração portuguesa no Brasil (1822-1945). São Paulo: Edusp; Fapesp, 2011.

MENDONÇA, R. F.; SIMÕES, P. G. Enquadramento: diferentes operacionalizações analíticas de um conceito. Revista Brasileira de Ciências Sociais, v. 27, n. 79, p. 187 - 235, 2012.

ORTIGÃO, R. As Farpas.Lisboa: David Corazzi, 1887. v. 11.

PINHEIRO, L. B. S. P. Francisco Gomes de Amorim e as primeiras abordagens literárias da Cabanagem. In: SOUZA, F. de et al. (Org.). Portugal e as migrações da Europa do Sul para a América do Sul. Porto: CEPESE, 2015. p. 418-434.

QUEIROZ, E. de. Uma campanha alegre. Lisboa: Companhia Nacional Editora, 1890. v. 1. . Uma campanha alegre. Lisboa: Companhia Nacional Editora, 1891. v. 2.

RIBEIRO, M. A. Gente de todas as cores: imagens do Brasil na obra de Gomes de Amorim. Máthesis, n. 7, p. $117-164,1998$.

SCOTT, A. S. Os portugueses. São Paulo: Contexto, 2012.

SERRÃO, J. A emigração portuguesa: sondagem histórica. 4. ed. Lisboa: Livros Horizonte, 1984.

SILVA, M. B. N. da. Prefácio. In: MENDES, J. S. R. Laços de sangue: privilégios e intolerância à imigração portuguesa no Brasil (1822-1945). São Paulo: Edusp; Fapesp, 2011. p. 23-26.

SMALL, M.L.; HARDING; D. J.; LAMONT, M. "Reavaliando cultura e pobreza". Sociologia \& Antropologia, v. 1, n. 2., p. 91 - 118, 2011.

VILLAS BÔAS, M. X.; PADILLA, Beatriz. Rumo ao Sul: emigrantes portugueses no Sul do Brasil. População e Sociedade, v. 2, n. 14-15, p. 115-129, 2007. 